\section{Efforts at Broadening Participation in the Sciences: An Examination of the Mentoring Experiences of Students from Underrepresented Groups}

\author{
Amy Prunuske, ${ }^{\dagger *}$ Janelle Wilson, $^{\ddagger}$ Melissa Walls, ${ }^{\S}$ Hannah Marrin, ${ }^{\dagger}$ \\ and Benjamin Clarke ${ }^{\dagger}$ \\ ${ }^{\dagger}$ Department of Biomedical Sciences and \$Department of Biobehavioral and Population Health, \\ University of Minnesota Medical School, Duluth, Duluth, MN 55812; 'Department of Sociology/ \\ Anthropology, University of Minnesota, Duluth, Duluth, MN 55812
}

\begin{abstract}
With the primary objective of attracting and retaining students from underrepresented backgrounds in the sciences, evaluation of one institution's program has been ongoing over the past three years. Interviews with mentors in the program followed by focus groups conducted with mentees reveal key factors that shape undergraduate students' research experiences. In the present study, attention is given to data gathered from 15 mentees in the program, the majority of whom have enrolled in community colleges, represent low socioeconomic backgrounds, and are nontraditional students. The results from focus groups with the mentees provide information on the benefits of participating in the program, characteristics of good mentors, challenges to the mentoring relationship, and the effects of underrepresented status on pursuit of advanced degrees. Comparisons of mentees' comments about the mentoring relationship with mentors' comments reveal similar themes and patterns while also demonstrating interesting differences. The qualitative findings are also juxtaposed with participants' responses on the Survey of Undergraduate Research Experiences. Taken together, the data enhance our understanding of the experiences of underrepresented students in faculty-mentored research programs and highlight challenges and perspectives of students who are transferring to the university from a community college.
\end{abstract}

\section{INTRODUCTION}

The biomedical research workforce in the United States does not reflect the diversity of the overall population, which is a challenge for adequately identifying and addressing the nation's research problems (Valantine and Collins, 2015). The racial/ethnic minority groups that are significantly underrepresented in the sciences (URMs) include blacks, Hispanics, and American Indian/Alaskan Natives with significant losses at every stage in the training process (Garrison, 2013). Underrepresentation can also be extended to nontraditional students and first-generation college students. In response to this glaring disconnect, there have been long-standing efforts by the U.S. federal government to provide funding opportunities aimed at broadening participation in biomedical research, and many of the funded programs incorporate a mentored research experience (National Institute of General Medical Sciences [NIGMS], 2015). During these research experiences, mentees work with a mentor to build their scientific knowledge, practice science, and be recognized as scientists. These three components are all important to developing mentees' science identities (Carlone and Johnson, 2007), and supportive mentorship positively impacts persistence, confidence, and satisfaction of trainees (Grandy, 1998). Thus, there is a need to understand what defines
Kenneth Gibbs, Monitoring Editor

Submitted January 12, 2016; Revised April 30, 2016; Accepted May 2, 2016

CBE Life Sci Educ September 1, 2016 15:ar26

DOI: $10.1187 /$ cbe.16-01-0024

*Address corresponding to: Amy Prunuske (amy prunuske(agmail.com).

(C) 2016 A. Prunuske et al. CBE-Life Sciences Education (๑) 2016 The American Society for Cell Biology. This article is distributed by The American Society for Cell Biology under license from the author(s). It is available to the public under an Attribution-Noncommercial-Share Alike 3.0 Unported Creative Commons License (http://creativecommons.org/licenses/ by-nc-sa/3.0)

"ASCB ${ }^{\circledR}$ " and "The American Society for Cell Biology $\circledR^{\prime \prime}$ are registered trademarks of The American Society for Cell Biology. 
an effective research and mentoring experience, particularly for underrepresented students.

Our institution is located in Minnesota, home to one of the largest American Indian (AI) populations in the country, with 11 federally recognized tribes. There are large educational disparities, with white students in Minnesota being twice as likely to graduate from high school and significantly more likely to complete college than AI students (Gonzalez et al., 2014). AI students and nontraditional students are significantly more likely to attend community college (Labov, 2012). Once these students transfer to a research university, they can encounter many obstacles that impede their progress to obtaining science degrees, including imperfect alignment of courses, financial difficulty, a lack of cultural capital, and increased nonacademic commitments (Packard et al., 2012). To address some of these challenges, our institution has had a long-standing undergraduate research program designed to increase underrepresented students transferring from the community college in pursuit of advanced degrees in the sciences.

While the primary aim of this program initially was to attract and support AI students, the program has expanded in its attempt to provide opportunities for students who are underrepresented not just with respect to race and ethnicity but also with respect to socioeconomic disadvantage. Participation in structured programs can provide first-generation college students with experience doing research, increased cultural capital, and necessary guidance to pursue a research career (Inkelas et al., 2007).

We previously conducted interviews with 15 research mentors involved in the program to gain insight into the mentors' experiences working with underrepresented undergraduates in the laboratory (Prunuske et al., 2013). We found a commitment of these faculty members to facilitate student critical-thinking and research skills but a relative lack of awareness about how students' backgrounds may complicate the mentoring relationship and impact students' decisions related to persistence.

Using the focus group method, our research team next turned our attention toward the mentees themselves, with the objective of discovering how they experience two undergraduate research programs-Bridges to the Baccalaureate and Pathways to Advanced Degrees in Life Sciences_-in particular, what they have gained through participation in the programs, qualities they believe a good mentor should possess, challenges to the mentoring relationship, and how they conceptualize the term "underrepresented." A key aim of the study is to help us understand the view of the students and to consider how their experiences and perceptions compare with those of the mentors. Gathering this kind of information enables us to more fully understand how both the mentors and their students experience the program, which provides insight into how to enhance the program going forward and offers tips or guidelines to others who might want to implement similar kinds of programs at their institutions.

\section{METHODS}

\section{Participants}

Our sample of mentees constitutes a purposive sample, that is, the subjects were selected based on their participation as mentees in either the Bridges to the Baccalaureate (Bridges) or the Pathways to Advanced Degrees in Life Sciences (Pathways) programs (see https://biomedical.umn.edu/programs/bridges -and-pathways for an overview of these programs). Both of these programs are designed to increase the enrollment in graduate school of students from underrepresented groups in science, with the primary target population being AI students and the inclusion of other URMs, first-generation college students, and students with significant financial need. These academic-enrichment programs at the University of Minnesota Medical School, Duluth campus, have been funded by the NIGMS for more than 15 years. The current Bridges and Pathways programs were established in 1996 and 2008, respectively.

The Bridges program provides professional development opportunities to students coming from two local community colleges: Lake Superior College in Duluth, Minnesota, and the Fond du Lac Tribal and Community College in Cloquet, Minnesota. The Pathways program provides professional development to juniors and seniors enrolled at the University of Minnesota, Duluth, with majors related to biomedical or biobehavioral sciences. Both the Bridges and Pathways programs are two-year paid appointments that begin with a full-time, eight-week summer boot camp consisting of workshops and laboratory experiences. Professional skill development includes critical reasoning, public speaking, experimental design, and career planning. Emphasis is placed on collaborative and teambased efforts to solve research questions. Critical reasoning during the boot camp is cultivated using a problem-based learning approach to explore new scientific ideas (Savery, 2006). Trainees are encouraged to mentor peers by providing positive feedback and sharing ideas. Faculty from the undergraduate campus, School of Medicine, and College of Pharmacy visit with the trainees to provide a research seminar and discuss their motivations for entering research careers. After completing the basic training, the trainees progress to faculty-mentored research projects for the next two years. During the academic year, the trainees meet monthly to discuss their research experiences. Each student completes a poster and oral presentation of his or her research as part of the program and has funding to travel to scientific conferences.

\section{Focus Groups}

The primary method of data collection for the current study involved focus groups with program trainees. As Billups (2012) notes, "Focus groups are a form of applied research, intended to help practitioners address organizational or programmatic challenges while exploring the experiences and attitudes of specific populations" (p. 7). Thus, this approach serves us well in our efforts to evaluate the effectiveness of the Bridges and Pathways programs and understand participants' experiences in the programs. Many researchers have noted that focus groups are "especially valuable when working with special populations, such as college students" (Billups, 2012, p. 4). Indeed, as Benmayor (2002) notes, "Students' testimonies provide deeper insight into how they negotiate the experience of college" (p. 99). The focus group setting and framework is conducive to open discussion and dialogue. More generally, employing a qualitative approach in this kind of investigation is advantageous, because "qualitative research is well-suited to answer questions about how learners and teachers make sense of the educational events in which they participate" (Hanson et al., 2011, p. 375). 
All study protocols were reviewed and approved by the University of Minnesota IRB (study \#1304S32081). Data collection occurred at the end of the summer program in 2013, and analysis continued over the next two years. All program trainees were recruited by an email from the program director explaining the purpose of the groups, study procedures, and an official invitation to participate. Incentives for participation included pizza, snacks, and beverages. Additionally, potential participants were informed that the knowledge gained from the focus groups would provide important information enabling researchers to evaluate the programs, thus potentially impacting education and training of future mentees in these programs.

Three 1-hour focus groups were conducted with four to five participants randomly assigned to each group. The total number of participants was 15 , with all eligible subjects choosing to participate. In each of the groups, a facilitator posed openended questions to the participants and a peer mentor in the program (H.M.) observed and took notes. (See Supplemental Materials for "Focus Group Questioning Route.) The facilitator was an undergraduate Research Assistant who had no affiliation with the program. The focus groups were audiotaped and transcribed.

The focus group questions were intended to enable us to discover and understand the benefits to the students of participating in the program, characteristics of a good mentor, challenges to the mentoring relationship, and how the students define "underrepresented." Employing the focus group method enabled us to examine the mentor-mentee relationship from the perspective of the mentees, in their own words. Combining these qualitative data with the interview data we had obtained from mentors (Prunuske et al., 2013) allowed us to ascertain how members of both groups experience the mentoring process.

\section{Data Analysis}

The focus group audio files were transcribed and independently coded by a white social scientist who has no direct affiliation with the program (J.W.), a white biomedical researcher who has served as an instructor in the program (A.P.), and an AI behavioral science researcher who has served as a mentor in the program (M.W.). As was the case in our previous study involving interviews with 15 mentors in these programs, we used an inductive approach rather than testing hypotheses. Our approach is consistent with Hanson et al. (2011), who state that "qualitative researchers might ... investigate the role of advisors and mentors, but they would not begin the study with a predetermined hypothesis" (p. 376). Furthermore, "information collected through interviews may provide a holistic understanding of the phenomena of interest from the perspective of participants" (p. 377). Indeed, the interview data from mentors and focus group data from mentees provided rich data with depth and nuance that would not have been possible if employing strictly quantitative approaches.

We used an inductive approach for initial open coding, organization, and notation of the data (Creswell, 1994; Lofland et al., 2005) Consistent with our previous study on the experiences of mentors, our key objective was to use a phenomenological approach to discover participants' subjective experiences as mentees in the program. For example, after our initial round of coding, all three coders independently identified "professional socialization" as a general theme. One of the coders approached the data with greater specificity and identified subthemes (e.g., "mentors as a guiding force," "mentors as sources of wisdom," "mentors as teachers," and "mentors as role models") that can be viewed as indicators or mechanisms of professional socialization. The greater specificity with respect to particular themes prompted extended discussion and accountable conceptualization and helped ensure validity in the researchers' conclusions about the substantive narrative(s) unfolding in the data.

\section{Survey}

The qualitative data were given the principal weight in our analysis, but to enhance our understanding of the mentoring program, we incorporated a mixed-methods approach. Shortly after completing the focus group, students in the program were emailed a link to complete an online survey including the customizable Survey of Undergraduate Research Experiences (SURE), which has been used to survey thousands of undergraduates from across the country on the learning gains associated with their research experiences (Lopatto, 2004). The survey data were anonymous and were analyzed parallel to the qualitative data, with the findings being compared during the interpretation stage (Ostlund et al., 2011). Descriptive statistics and graphical analysis of the survey data were completed in Microsoft Excel.

\section{RESULTS}

Undergraduates participating in a National Institutes of Health (NIH)-funded program designed to increase the number of underrepresented students pursuing advanced science degrees were invited to participate in a focus group to discuss their experiences with the program. The program consists of an eight-week summer program designed to build the students' self-efficacy followed by a two-year mentored research experience in a faculty member's laboratory. The focus group occurred at the end of the summer program; at this point, the amount of mentored research experience was variable among participants, with five of the students joining their labs that summer and 10 of the students having had at least one year of mentored lab experience. We had a $100 \%$ response rate, with all of the students $(n=15)$ choosing to participate in the focus groups; the summary demographics for the participating students are reported in Table 1. Ten of the students in the focus groups were part of the Bridges program and were enrolled at two local community colleges. The five students in the Pathways program, two of whom had previously been in the Bridges program, were of junior status and were enrolled at the research university. Students in the program were majoring in biology, chemistry, engineering, or mathematics and were completing mentored research on a range of topics, including cancer biology, conservation biology, Indigenous community research, and auditory physiology. Of the students in the focus groups, eight were male and seven were female, with an average age of 29 years and a range of 21-38 years. There were two AI students and one African-American student; 14 of the students had significant financial need.

We provide a descriptive account of key themes that emerged in the data, and where relevant, we juxtapose findings from this study with findings from our previous interviews with the mentors (Prunuske et al., 2013). We also interpret some of the 
TABLE 1. Mentee demographics

\begin{tabular}{ll}
\hline Demographic & \multicolumn{1}{c}{ Value } \\
\hline Program & \\
$\quad$ Bridges & $66.67 \%(10)$ \\
$\quad$ Pathways & \\
Sex & $33.33 \%(5)$ \\
$\quad$ Male & $53.33 \%(8)$ \\
$\quad$ Female & $46.67 \%(7)$ \\
Underrepresented status & \\
$\quad$ Financial need & $93.33 \%(14)$ \\
$\quad$ Ethnic minority & $20 \%$ \\
& $13 \%$ Native American (2) \\
& $6 \%$ African American (1) \\
Age & \\
$21-25$ yr & $40 \%(6)$ \\
$26-30$ yr & $13.33 \%(2)$ \\
$31-35$ yr & $33.33 \%(5)$ \\
$36+$ yr & $13.34 \%(2)$ \\
\hline
\end{tabular}

aBridges students are enrolled at a community college, and Pathways students are enrolled at a research university. Two of five Pathways students were previously enrolled in the Bridges program.

themes in relation to the students' responses to the online SURE, for which 12 of the 15 students responded.

\section{Benefits of Being a Mentee in the Program}

The first area explored with the mentees was the benefits of having participated in the program. Mentees report, overall, a positive experience in the program. In particular, the participants express that their thinking has been transformed, as evidenced in statements such as "[The program] teaches you how to think differently" and "[It] really helps develop skills that you didn't know you had." Throughout the focus group data, we see evidence of how participation in the program opens access to students and transforms their aspirations. The following quotes from two female mentees aptly capture this:

"I never thought (getting a $\mathrm{PhD}$ ) was possible and now that we've done the things that we've done. I thought, I'm smarter than I thought I was, wow."

"I think it's a wonderful program and I know that without it being here, I never would have imagined myself getting, even the possibility of getting a Ph.D., or going beyond my Bachelor's degree, you know I just thought that was good enough, but now I think, shoot for the stars and all that stuff ... I'm very grateful for the program."

Mentees comment on the opportunities they have been given to do research and how their active involvement in research has helped them to gain confidence and has opened up new possibilities. Based on the survey, only two students in the program reported any prior research experience and likely included the two students who had been in the Bridges program before transferring to the research university. The program benefits that were noted by the mentors are consistent with the mentees' observations, as we had noted previously: "Mentors highlighted enabling students to learn about science, helping them to discover their aptitudes and interests, and building students' confidence" (Prunuske et al., 2013, p. 405).
The focus group data suggest that mentees are gaining much more than learning technical skills or discipline-specific knowledge; they are also acquiring the skills necessary for professional socialization. In fact, some students expressed surprise at the depth of what they gained from the lab experience; one of the mentees explained that his participation in the program transformed his undergraduate experience:

"Like I was just a student going to classes before, and I wanted to get into research and I pictured it as being like, kind of like a job in the cafeteria, only instead of washing dishes and serving tuna mac, you're just doing some busy work around a laboratory, but it would look good on a resume, and this program [it] just changed [from what I expected] ... I actually do research in a lab and get the opportunity to do presentations ... I feel a lot more confident talking to professors now than I did before "it's made a huge difference."

The students drew a contrast between their experiences of working in the laboratory through the program and their regular lab classes. In the former, they find that they are taking ownership of the research project, whereas in typical lab courses, they are, as one male participant stated, “Aping' what the T.A. shows you how to do and just repeating it." The mentored research experience offered through the program "has been a chance to actually have to do it for a real reason and have to get good results." This, too, is consistent with what the mentors expressed to us regarding the importance of the mentees' active involvement in research. Mentors noted that, in addition to having mentees work on faculty members' research projects, it is also important to "get the students to the point of testing their own hypotheses" (Prunuske et al., 2013, p. 405). One mentor succinctly stated that the primary objective is exposing students to the scientific world such that they are able to do "the scientific method from start to finish" (p. 405).

On the SURE, 11/12 students reported that the experience was much better than they had expected, and the other student reported it had met his/her expectations. The top areas of gain that students identified based on their participation in the program included "confidence in my potential to pursue a career in science" and "ability to work in groups" (Figure 1). A previous study found that, for undergraduates who were not enrolled at a community college, the top areas of gain were "readiness for demanding research" and "understanding of research process in your field" (Lopatto, 2004). Participation in the program was critical to building students' self-efficacy to pursue a science career.

\section{Characteristics of a Good Mentor}

The mentees expressed that the most important factor in selecting a mentor is the personality of the mentor. For example, a female mentee stated: "I'm less concerned about the subject, and more about the person. I want someone who seems friendly and will be gentle." Additionally, a male mentee noted the research that his mentor does but added that it was the mentor's personality that especially influenced his desire to work with him: "The research he does I was interested in, but mostly ... I got a really cool vibe from his personality when I talked to him that one time." This theme was quite prominent in the data and was especially prominent among female participants. Female participants commented 31 times and male participants 


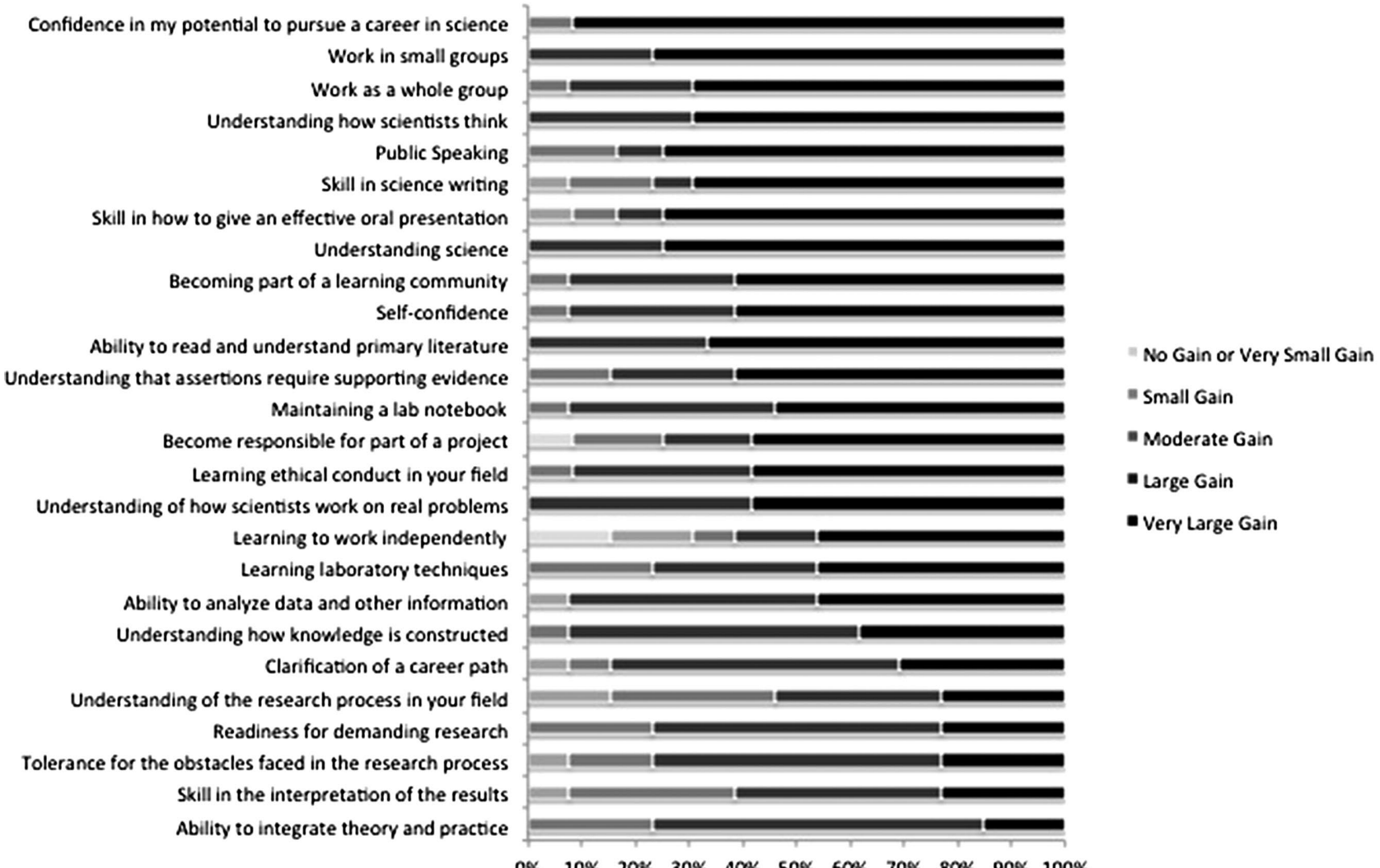

FIGURE 1. Reported gains on the SURE after participation in Bridges and Pathways programs. Students reported whether they had experienced no gain or very small gain, small gain, moderate gain, large gain, or very large gain on an online survey. Questions were reordered such that areas of very large gain are at the top.

commented 18 times on the importance of personality to the mentoring relationship. In contrast, female participants commented five times and male participants commented 14 times on the importance of the mentor's research and his/her professional status. It was also clear that the program helped to establish a peer and professional network that students used when selecting a mentor. As one female participant noted, classmates in the cohort are a "better resource for picking mentors than if you were just sticking with reading their online research paragraphs."

Importantly, when we were interviewing the mentors, we rarely heard about personality being an important factor in who they decided to accept into the lab. Rather, we found that "some factors the mentors considered included [the potential mentee's] personal connection to the focus of the lab (e.g., family member with cancer), a student's ability to make a commitment, a student's comfort with killing animals, and whether the mentor felt a student had a 'high level of innate intelligence'" (Prunuske et al., 2013, p. 406).

In terms of what is needed to be an effective mentor, the students expressed wanting mentors who would engage with them. One male participant described a desired characteristic of a mentor as the "quality of wanting to get to know people and see what makes them tick." In addition, the importance of communication was emphasized: "I want to be able to go to that person and be like, I have no idea what you're talking about."
The mentees also highlighted the role of the professor as being more academic in contrast to a graduate student who they could talk to about everything. On the survey, $66 \%$ of the students indicated that their supervisors were outstanding teachers and mentors, and all of the students reported that their mentors were at least average. When we asked mentors what is needed to be an effective mentor, the majority indicated the significance of enthusiasm, as the mentor's excitement can have a contagious effect on the mentee. Mentors also noted that it is crucial for mentors "to be able to explain, at a nonexpert level, and help the student understand how his or her project fits into the bigger picture" (Prunuske et al., 2013, p. 405). With respect to personality traits, some of the mentors did emphasize that "mentors should not be too critical, because that may turn people off to science ... [rather, mentors should be] empathetic and patient" (p. 405).

\section{Challenges to the Mentoring Relationship}

We asked participants in both groups to identify challenges to the mentoring relationship. The importance of communication and the gap between expert and novice was expressed by a female mentee, who stated: "[The mentor] has a lot of knowledge in his field, but he doesn't give you that knowledge." The students articulated a lack of communication as a significant factor to why students stop showing up in the lab. A female participant indicated that you need "enough communication to 
make sure that you're doing things correctly and you're liking what you're doing," and if that is absent, "then it's pretty easy to just kinda fade away."

The need for constructive feedback was critical for both the mentors and mentees, and its absence can easily lead to students leaving the lab if, as expressed by a female mentee, "the thought of going into your lab each day fills you with dread because you're so worried you're gonna make a mistake." Mentors had less understanding about what causes students to leave and instead emphasized that there "are just going to be people who are not going to fit."

Students also voiced concern in cases in which the faculty member may appear to be too ambitious. A male mentee stated that, if the professor is "really into their own career to a crazy level, that might be a red flag that they're into this because they want some slave labor." A corollary to this was the challenge of the time commitment demanded of mentors, in particular working with undergraduate students as opposed to graduate students or postdoctoral fellows. Returning, again, to what we learned from the mentors about the challenges of mentoring: "training undergraduates in the lab is a significant time commitment and may mean less research productivity potential as compared with a graduate student" (Prunuske et al., 2013, p. 406). Additionally, mentors expressed that mentoring of undergraduates is not always recognized or rewarded and was described by mentors as 'a career killer' (i.e., this kind of work will not get one promoted"; p. 405).

\section{Mentees' Definitions of the Term "Underrepresented"}

The students acknowledged that they were more diverse than most of the students at the university but were similar to the mentors in that they had a limited understanding of the relevance of this diversity. As was noted by one of the participants, "We are pretty diverse compared with everybody else here at UMD. Yeah it scares me. I'm still intimidated by that, I don't know why." While the focus group participants discussed, in an abstract way, possible meanings of the term "underrepresented," including "rural," "underprivileged," or "having membership in a racial/ethnic minority group," the examples they provided from their own direct experiences pointed toward particular ways in which they see themselves as perhaps qualifying as underrepresented students. For the majority of these students attending college is an experience that sets them apart from others in their families. One of the female participants shared,

\footnotetext{
"The Bridges program it does talk about how they try to help people whose parents may not, my mom went to college but I think she only graduated with a two-year degree, but I think they try to help people whose parents, there isn't a history in their family of moving on into getting college degrees."
}

Another female participant noted, "My parents were pretty poor when I was growing up and they were both alcoholics." The vast majority of the students in our sample demonstrate definite financial need.

Interestingly, while the meaning of "underrepresented" as described by the mentors focused primarily on racial/ethnic/ social class categories, the mentees in this study focused more on age and how this contributed to the feeling of being different from other students at the university, which puts them in the category of "nontraditional students." This was not experienced as a challenge during the time that some of these students were at the community college. As one female participant said, "At [the community college] there's a lot of diversity, there's 60 -year-olds and 16-year-olds." Going from that environment to the university setting clearly affected their degree of comfort in the academic setting.

\section{Pursuit of Postgraduate Degree}

While the Bridges and Pathways programs are intended to encourage postgraduate work, the mentee's age appears to be a key deterrent to continuing study beyond the bachelor's degree. One of the male mentees stated,

"I don't know if I should just get a job like this that pays well, at some private company or something, and just be a lab tech for the rest of my life. I want to be a doctor or a research scientist, I really do, but 38 years old, that's kind of old, you know."

Another factor contributing to whether a student chooses to pursue the advanced degree was advice from the mentor. We had found that many of the mentors wanted to make sure their mentees were aware of the options available to them following the bachelor's degree, while also being brutally honest about the unpleasant aspects of having an academic career. For instance, one of the mentors had stated: "I think the academic life is a very difficult one, and if they bring it up with me, I usually tell them to talk to several people and find out about ... quality of life issues" (Prunuske et al. 2013, p. 407). It was clear that this was the message that some of the students in the program were receiving. For example, a female participant said the following about her mentor: "He doesn't see that it [getting a $\mathrm{PhD}$ in a biology field] has that much potential. So he's been really honest and I've appreciated that with him." While the honesty and openness of the mentors is appreciated by the mentees, it may be that this kind of advice militates against a key goal of the program, which is to encourage the students to continue on to graduate school. Additionally, it may counteract some of the new confidence, sense of self-efficacy, and future career possibilities that the mentees now possess.

\section{DISCUSSION}

Our findings from the focus groups with the mentees, combined with the findings from the interviews we previously conducted with mentors, provide an important understanding of the mentoring relationship from both the mentee and mentor perspectives. The students highlighted the value of being a participant in a program designed to bolster their confidence and self-efficacy. Working with the research mentors created connections and opportunities for the mentees. As detailed in the preceding section, there are many areas in which the mentors' and the mentees' perceptions and experiences match, and it is clear that, for the most part, the mentoring relationship —as well as the program itself-is experienced in a positive manner among both mentor and mentee participants.

For most of the students in our program, many of whom were enrolled at the community college, the experience was transformative and gave them a goal for finishing their undergraduate degree. Others have found that participation in 
research experiences broadens underrepresented students' interests and goals (Thiry and Laursen, 2011). This is in contrast to reports for majority students already enrolled at research universities where participation in an undergraduate research experience reinforced a prior interest in graduate school (Villarejo et al., 2008). Among the student participants in our study, support from mentors was critical in professional socialization, and support from one another was essential for successfully navigating the culture of the research institution (Gibau, 2015). The program gave the students the necessary disciplinary skills, but more than that, it provided the opportunity to build confidence and to have the affirmation from mentors to consider graduate school an attainable goal (Byars-Winston, 2014).

Another important finding was that students identified their somewhat "older" age as a key way in which they felt diverse or "underrepresented" at the research university. The average age of students attending community colleges is 29 (American Association of Community Colleges, 2016), consistent with the students in our study, whereas only $10 \%$ of enrolled students at the research university are over the age of 25 . In addition to the challenge of occupying the nontraditional student role, students transferring from community colleges must navigate articulation agreements, which have become articulation bureaucracies, "stunning [in their] complexity and nuance," thus sometimes having the effect of hampering, rather than assisting, "students' academic progress" (Handel, 2013, p. 4). In general, the students find themselves in an environment "that is often significantly different from the one they left behind in size, location, cost, and academic demands" (Handel, 2013, p. 9). Whereas "community colleges are uniquely structured to provide ... intensive, personalized support" (Jenkins, 2013), the university to which students have transferred does not typically operate this way. Studies have shown that students attending community colleges typically report "positive feelings about their community college experiences, citing inspiring professors, peer support, and helpful advising," yet once the students are enrolled at the four-year institution, students' sentiments "turned negative" (Tilsley, 2012). Given these factors, "it is especially important to engage transfer students early" (Handel, 2013, p. 9). The Bridges and Pathways programs are very valuable in helping to ease the transition for our student participants. Their participation in the programs puts the students on a path to obtaining their four-year degree as well as encouraging them to consider pursuing advanced degrees. We find through the focus group data that our participants have directly benefited from the experience of being in a cohort program that puts them in direct contact with mentors/professors and fellow students and gives them hands-on experiences in the laboratory.

Our work reveals interesting information about characteristics that students consider when selecting a mentor. The ideal qualities of a mentor, including important personality traits like enthusiasm and compassion, have been highlighted by others (Cho et al., 2011). These traits seem to be particularly important for the women in our sample-more so than status and prestige. This finding may relate to the fact that fewer women train in the elite labs that serve as the gateway to the professoriate (Sheltzer and Smith, 2014). Other reported factors important for successful mentoring that are consistent with our results include having the time to meet regularly, institutional support for mentoring, and mentor's ability to tailor the support to the mentee's needs (Cho et al., 2011).

Our data also reveal particular challenges. For example, a challenge for the programs is that both the mentees and mentors reported that, in some cases, the mentors were discouraging the mentees from continuing on in science due to a hypercompetitive system (Alberts et al., 2014). It appears that, consistent with social cognitive career theory, some of the mentors are recommending career decisions based on their personal values, which may not be consistent with those of the students (Gibbs and Griffin, 2013). Thus, an unintended consequence of the competitive environment is that it may deter some students from pursuing advanced degrees. In addition, the finding that age is an important factor in contributing to students' decisions to pursue advanced degrees needs to be considered in the context of time to finish degree and possible expansion of master's degree programs (NIH, 2012).

\section{CONCLUSION}

There is commitment nationally to improve the quality of mentoring for students from underrepresented groups in the biomedical sciences through the National Research Mentoring Network (https://nrmnet.net). The first author (A.P.), with another National Research Mentoring Network master facilitator, led a mentoring workshop for the mentors in the program. The training included the theory-based Entering Mentoring curriculum, which has been shown to be an effective way to build mentor self-efficacy in discussing factors like race, gender, and socioeconomic class (Pfund et al., 2006). The training also incorporated anonymous mentee quotes from the focus groups to encourage mentors to reflect on how their own perspectives might differ from those of the mentees. All of the mentors who participated in the training indicated that the section on addressing issues of diversity was the most useful and interesting section, with one mentor stating, "The ideas about diversity and our assumptions about what students perceive themselves as diverse brought about by the stories of some of the participants were the most valuable part of the training for me." This kind of feedback reinforces the concept that mentor training can provide the necessary time and space for reflection that is an important component of cultural humility and will help to support diversification of the scientific workforce (Yeager and Bauer-Wu, 2013). We are also developing corresponding mentee training to use during the student summer development program to help raise students' understanding of these issues, to encourage reflection, and to improve mentee communication skills.

A limitation of our study is that it was performed at a single institution. However, mentees were working with mentors in a number of departments, and our survey results were discussed in comparison with results that were previously collected across several institutions. We also found that many of the themes are consistent with ideas in the literature about mentoring. The applicability and generalizability of the results will require additional studies at other institutions. Future research on the success of this program will need to look at the long-term outcomes as students transition into graduate programs. We are also exploring alternative models of mentoring to the mentor-mentee dyad, including putting students into collaborative-learning research groups and understanding the importance of peer mentoring, which was an emerging theme in our data. The 
mentoring workshop and exploration of the efficacy of peer mentoring are direct outgrowths of our study and thus illustrate ongoing efforts shaped by important research findings.

Our study highlights that understanding the myriad ways in which students are "underrepresented" is crucial. As evidenced in our sample, in addition to racial/ethnic minority status, being first-generation college students, and being a little "older" than most of their classmates shaped these students' perceptions and experiences in college as well as their long-term goals. Working more closely with community colleges and better understanding unique circumstances of transfer students could potentially be another "takeaway" for those at other institutions who wish to broaden participation in the sciences at their universities and beyond.

\section{ACKNOWLEDGMENTS}

Funding for this project was received from NIGMS 5R25GM086669-07 and NIGMS 2R25GM053403-12. Mary Cannedy-Clarke and Shannon RedBrook provided excellent administrative support for the programs, and Garrett Soper conducted and transcribed the focus groups.

\section{REFERENCES}

Alberts B, Kirschner M, Tilghman S, Varmus M (2014). Rescuing US biomedical research from its systemic flaws. Proc Natl Acad Sci USA 111, 5773-5777.

American Association of Community Colleges (2016). Students at Community Colleges. www.aacc.nche.edu/AboutCC/Trends/Pages/ studentsatcommunitycolleges.aspx (accessed 1 February 2016).

Benmayor R (2002). Narrating cultural citizenship: oral histories of first-generation college students of Mexican origin. Soc Justice 29, 96-121.

Billups FD (2012). Conducting focus groups with college students: strategies to ensure success. Association for Institutional Research-Professional File 127, 1-12. http://scholarsarchive.jwu.edu/cgi/viewcontent.cgi?article $=10028$ context=research_methodology (accessed 4 January 2016).

Byars-Winston A (2014). Toward a framework for multicultural STEM-focused career interventions. Career Dev Q 62, 340-357.

Carlone HB, Johnson A (2007). Understanding the science experience of successful women of color: science identity as an analytic lens. J Res Sci Teach 44, 1187-1218.

Cho CS, Ramanan RA, Feldman MD (2011). Defining the ideal qualities of mentorship: a qualitative analysis of the characteristics of outstanding mentors. Am J Med 124, 453-458.

Creswell J (1994). Research Design: Qualitative and Quantitative Approaches, Thousand Oaks, CA: Sage.

Garrison H (2013). Underrepresentation by race-ethnicity across stages of U.S. science and engineering education. CBE Life Sci Educ 12, 357-363.

Gibau GS (2015). Examining the experiences of underrepresented students in intervention programs. CBE Life Sci Educ 14, ar28.

Gibbs KD, Griffin KA (2013). What do I want to be with my PhD? The roles of personal values and structural dynamics in shaping the career interests of recent biomedical science PhD graduates. CBE Life Sci Educ 12, 711723.

Gonzalez J, Simard E, Baker-Demaray T, Iron Eyes C (2014). The internalized oppression of North American indigenous peoples. In: Internalized Oppression: The Psychology of Marginalized Groups, ed. EJR David, New York: Springer, 31-56.
Grandy J (1998). Persistence in science of high-ability minority students: results of a longitudinal study. J High Educ 69, 589-620.

Handel SJ (2013). Transfer as Academic Gauntlet: The Student Perspective, New York: College Board Advocacy \& Policy Center. http://media .collegeboard.com/digitalServices/pdf/advocacy/policycenter/transfer -academic-gauntlet-student-perspective-report.pdf (accessed 15 February 2016).

Hanson JL, Balmer DF, Giardino AP (2011). Qualitative research methods for medical educators. Acad Pediatr 11, 375-386.

Inkelas KK, Daver AE, Vogt KE, Leonard JB (2007). Living-learning programs and first-generation college students' academic and social transition to college. Res High Educ 48, 403-434.

Jenkins R (2013). What about community colleges? Chron High Educ, January 15. http://chronicle.com/article/What-About-Community -Colleges-/136671 (accessed 1 February 2016).

Labov J (2012). Changing and evolving relationships between two- and fouryear colleges and universities: they're not your parents' community colleges anymore. CBE Life Sci Educ 11, 121-128.

Lofland J, Snow D, Anderson L, Lofland L (2005). Analyzing Social Settings: A Guide to Qualitative Observation and Analysis, 4th ed., Belmont, CA: Wadsworth.

Lopatto D (2004). Survey of Undergraduate Research Experiences (SURE): first findings. Cell Biol Educ 3, 270-277.

National Institute of General Medical Sciences (2015). Current Programs in the Division of Training, Workforce Development, and Diversity. www.nigms.nih.gov/Training/Pages/TWDPrograms.aspx (accessed 21 December 2015).

National Institutes of Health (2012). Biomedical Workforce Working Group Report. http://acd.od.nih.gov/biomedical_research_wgreport.pdf (accessed 30 December 2015).

Ostlund U, Kidd L, Wengstrom Y, Rowa-Dewar N (2011). Combining qualitative and quantitative research within mixed method research designs: a methodological review. Int J Nurs Stud 48, 369-383.

Packard BW, Gagnon JL, Senas A (2012). Navigating community college transfer in science, technical, engineering, and mathematics fields. Community Coll J Res Pract 36, 91-14.

Pfund C, Pribbenow C, Branchaw J, Miller Lauffer S, Handelsman J (2006). The merits of training mentors. Science 311, 473-474.

Prunuske A, Wilson J, Walls M, Clarke B (2013). Experiences of mentors training underrepresented undergraduates in the research laboratory. CBE Life Sci Educ 12, 403-409.

Savery JR (2006). Overview of problem-based learning: definitions and distinctions. Interdiscip J Problem-Based Learn 1(1), http://dx.doi .org/10.7771/1541-5015.1002.

Sheltzer JM, Smith JC (2014). Elite male faculty in the life sciences employ fewer women. Proc Natl Acad Sci USA 111, 10107-10112.

Thiry H, Laursen SL (2011). The role of student-advisor interactions in apprenticing undergraduate researchers into a scientific community of practice. J Sci Educ Technol 20, 771-784.

Tilsley A (2012). STEM pathways. Inside Higher Ed, November 1. www insidehighered.com/news/2012/11/01/new-focus-helping-community -college-students-stem-fields-four-year-degree (accessed 12 February 2016).

Valantine HA, Collins FS (2015). National Institutes of Health addresses the science of diversity. Proc Natl Acad Sci USA 112, 12240-12232.

Villarejo J, Barlow AEL, Kogan D, Veazey BD, Sweeney JK (2008). Encouraging minority undergraduates to choose science careers: career paths survey results. CBE Life Sci Educ 7, 394-409.

Yeager KA, Bauer-Wu S (2013). Cultural humility: essential foundation for clinical researchers. Appl Nurs Res 26, 251-256. 